\title{
In vitro piperaquine susceptibility is not associated with the Plasmodium falciparum chloroquine resistance transporter gene
}

\author{
Aurélie Pascual1,2,3, Marilyn Madamet ${ }^{3,4,5}$, Lionel Bertaux ${ }^{3,4}$, Rémy Amalvict ${ }^{1,2,3,5}$, Nicolas Benoit 1,2,3, \\ Dominique Travers ${ }^{1,2,3}$, Julien Cren ${ }^{3,4}$, Nicolas Taudon ${ }^{3,4}$, Christophe Rogier ${ }^{6}$, Daniel Parzy ${ }^{3,4}$, \\ Bruno Pradines ${ }^{1,2,3^{*}}$ and The French National Reference Centre for Imported Malaria Study Group
}

\begin{abstract}
Background: Dihydroartemisinin-piperaquine is a new ACT that is administered as single daily dose for three days and has been demonstrated to be tolerated and highly effective for the treatment of uncomplicated Plasmodium falciparum malaria. Piperaquine was used alone to replace chloroquine as the first-line treatment for uncomplicated malaria in China in response to increasing chloroquine resistance in the 1970s. However, the rapid emergence of piperaquine-resistant strains that resulted in the cessation of its use in China in the 1980s, suggests that there is cross-resistance between piperaquine and chloroquine. Very few data are available on cross-resistance between piperaquine and chloroquine, and the data that do exist are often contradictory.
\end{abstract}

Methods: In total, 280 P. falciparum isolates, collected between April 2008 and June 2012 from patients hospitalized in France with imported malaria from a malaria-endemic country, were assessed ex vivo for piperaquine and chloroquine susceptibilities by using the standard 42-hour 3H-hypoxanthine uptake inhibition method. The chloroquine resistance-associated mutation K76T in pfcrt was also investigated for the 280 isolates.

Results: The $I C_{50}$ for piperaquine ranged from $9.8 \mathrm{nM}$ to $217.3 \mathrm{nM}$ (mean $=81.3 \mathrm{nM}$. The $I C_{50}$ for chloroquine ranged from $5.0 \mathrm{nM}$ to $1,918 \mathrm{nM}$ (mean $=83.6 \mathrm{nM}$. A significant but low correlation was observed between the Log $I_{50}$ values for piperaquine and chloroquine $(r=0.145, p<0.001)$. However, the coefficient of determination of 0.021 indicates that only $2.1 \%$ of the variation in the response to piperaquine is explained by the variation in the response to chloroquine. The mean value for piperaquine was $74.0 \mathrm{nM}$ in the Pfcrt K76 wild-type group (no $=125$ ) and $87.7 \mathrm{nM}$ in the $76 \mathrm{~T}$ mutant group $(\mathrm{no}=155)$. This difference was not significant $(\mathrm{p}=0.875$, Mann Whitney U test).

Conclusions: The present work demonstrates that there was no cross-resistance between piperaquine and chloroquine among $280 P$. falciparum isolates and that piperaquine susceptibility is not associated with pfcrt, the gene involved in chloroquine resistance. These results confirm the efficacy of piperaquine in association with dihydroartemisinin and support its use in areas in which parasites are resistant to chloroquine.

Keywords: Malaria, Plasmodium falciparum, Anti-malarial, Resistance, in vitro, Molecular marker, Piperaquine, Chloroquine, pfcrt

\footnotetext{
* Correspondence: bruno.pradines@free.fr

'Département d'Infectiologie de Terrain, Unité de Parasitologie, Institut de Recherche Biomédicale des Armées, Marseille, France

${ }^{2}$ Aix Marseille Université, Unité de Recherche sur les Maladies Infectieuses et Tropicales Emergentes, UM 63, CNRS 7278, IRD 198, Inserm 1095, Marseille, France

Full list of author information is available at the end of the article
} 


\section{Background}

Over the past 20 years, many strains of Plasmodium falciparum have become resistant to chloroquine and other anti-malarial drugs [1]. In 2002, the World Health Organization (WHO) recommended that artemisininbased combination therapy (ACT) be used to treat all cases of uncomplicated malaria. Different formulations of ACT have been evaluated: artesunate-sulphadoxinepyrimethamine, artesunate-amodiaquine, artemetherlumefantrine, artesunate-mefloquine, artesunatechlorproguanil-dapsone, artesunate-pyronaridine and, more recently, dihydroartemisinin-piperaquine. Most of these formulations are available as fixed-dose coformulations, which are convenient, facilitate improved adherence and help prevent misuse.

Dihydroartemisinin-piperaquine (Artekin ${ }^{\circ}$, Duo-Cotecxin ${ }^{\circ}$, Eurartesim $^{\circ}$ ) is a new ACT that is administered as single daily dose for three days and has been demonstrated to be tolerated and highly effective for the treatment of uncomplicated malaria in Asia [2,3] and the treatment of uncomplicated $P$. falciparum malaria in Africa $[4,5]$. Dihydroartemisinin-piperaquine seems to have a better post-treatment prophylactic effect than artemetherlumefantrine [6-8] or artesunate-amodiaquine [9]. Since 2012, dihydroartemisinin-piperaquine has been available for the treatment of uncomplicated malaria in France.

Piperaquine, a bisquinoline, was used alone to replace chloroquine as the first-line treatment for uncomplicated malaria in China in response to increasing chloroquine resistance in the 1970s. However, the rapid emergence of piperaquine-resistant strains resulted in the cessation of its use in China in the 1980s [10].

This rapid emergence of piperaquine-resistant strains suggests that there is cross-resistance between piperaquine and chloroquine. Very few data are available on crossresistance between piperaquine and chloroquine, and the data that do exist are often contradictory. A positive significant correlation was found for 63 isolates from the China-Myanmar border area $(\mathrm{r}=0.79, \mathrm{p}<0.0001)$ [11], 54 isolates from Papua New Guinea $(\mathrm{r}=0.51, \mathrm{p}<0.001)$ [12] and 103 isolates from Cameroon $(r=0.257, p<0.05)$ [13], whereas no significant correlation was observed for 199 isolates from Uganda $(\mathrm{r}=0.121, \mathrm{p}=0.15)$ [14], 115 culture-adapted isolates from Kenya $(r=0.16, p=0.13)$ [15], 23 strains from 16 different countries $(r=0.199, p=$ 0.366) [16] or 181 isolates of imported malaria from 19 countries $(\mathrm{r}=0.036, \mathrm{p}=0.634)$ [17]. In addition, very few data are available on the association between piperaquine susceptibility and polymorphisms in the gene involved in chloroquine resistance, pfcrt ( $P$. falciparum chloroquine resistance transporter) [18].

The objectives of the present work were to evaluate the cross-resistance between piperaquine and chloroquine in
280 fresh isolates of $P$. falciparum and to investigate the association between piperaquine and chloroquine susceptibility and the K76T mutation in pfcrt.

\section{Methods}

\section{Patients and sample collection}

In total, 280 P. falciparum isolates were collected between April 2008 and June 2012 from patients hospitalized in France with imported malaria from a malaria-endemic country (Angola, Benin, Burkina Faso, Cameroon, Central African Republic, Chad, Comoros, Congo, Ivory Coast, Gabon, Gambia, Ghana, Guinea, India, Madagascar, Mali, Mauritania, Mozambique, Niger, Senegal, Thailand, Togo, Zambia). Informed consent was not required for this study because the sampling procedures and testing are part of the French national recommendations for the care and surveillance of malaria. Venous blood samples were collected in Vacutainer ACD tubes (Becton Dickinson, Rutherford, NJ, USA) before treatment and were transported at $4^{\circ} \mathrm{C}$ from French hospitals located in Aix en Provence, Bordeaux, Chambery, Frejus, Grenoble, Lyon, Marseille, Metz, Montpellier, Nice, Nimes, Pau, Toulon, Toulouse, and Valence to the Institute of Biomedical Research of the French Army (IRBA) in Marseille within 72 hours of collection. The Case Report Form was provided at the same time, either as a paper copy or electronically.

Thin blood smears were stained using a RAL kit (Réactifs RAL, Paris, France) and were examined to determine $P$. falciparum density and confirm mono-infection. Parasitized erythrocytes were washed three times with RPMI 1640 medium (Invitrogen, Paisley, UK) buffered with $25 \mathrm{mM}$ HEPES and $25 \mathrm{mM} \mathrm{NaHCO}$. If parasitaemia exceeded $0.5 \%$, infected erythrocytes were diluted to $0.5 \%$ with uninfected erythrocytes (human blood type $\mathrm{A}+$ ) and re-suspended in RPMI 1640 medium supplemented with $10 \%$ human serum (Abcys S.A. Paris, France), for a final haematocrit of $1.5 \%$. The susceptibility of the 280 isolates was assessed without culture adaptation.

\section{Drugs}

Piperaquine was obtained from Shin Poong Pharm Co. (Seoul, Korea) and was dissolved first in methanol and then diluted in water to obtain final concentration ranging from 0.8 to $1,000 \mathrm{nM}$. Chloroquine was purchased from Sigma (Saint Louis, MO, USA) and was dissolved first in methanol and then diluted in water to final concentrations ranging from $5 \mathrm{nM}$ to $3,200 \mathrm{nM}$. Batches of plates were tested and validated using the chloroquine-susceptible 3D7 strain (West Africa) and the chloroquine-resistant W2 strain (Indochina) (MR4, Virginia, USA) in three to six independent experiments using the conditions described in the paragraph below. The two strains were synchronized twice with sorbitol before use [19], and clonality 
was verified every 15 days using PCR genotyping of the polymorphic genetic markers $m s p 1$ and $m s p 2$ and using microsatellite loci $[20,21]$ and additionally verified each year by an independent laboratory from the Worldwide Anti-malarial Resistance Network (WWARN).

\section{Ex vivo assay}

For ex vivo isotopic microtests, $200 \mu \mathrm{l} /$ well of the suspension of synchronous parasitized red blood cells (final parasitaemia, 0.5\%; final haematocrit, $1.5 \%$ ) were distributed in 96-well plates pre-dosed with anti-malarial drugs. Parasite growth was assessed by adding $1 \mu \mathrm{Ci}$ of tritiated hypoxanthine with a specific activity of $14.1 \mathrm{Ci} /$ mmol (Perkin-Elmer, Courtaboeuf, France) to each well at time zero. The plates were then incubated for 42 hours in controlled atmospheric conditions that consisted of $10 \% \mathrm{O}_{2}, 5 \% \mathrm{CO}_{2}$, and $85 \% \mathrm{~N}_{2}$ at $37^{\circ} \mathrm{C}$ with a humidity of $95 \%$. Immediately after incubation, plates were frozen and then thawed to lyse erythrocytes. The content of each well was collected on standard filter microplates (Unifilter GF/B; Perkin-Elmer) and washed using a cell harvester (Filter-Mate Cell Harvester; Perkin-Elmer). Filter microplates were dried, and $25 \mu \mathrm{l}$ of scintillation cocktail (Microscint O; Perkin-Elmer) was placed in each well. Radioactivity incorporated in nucleotides by the parasites was measured with a scintillation counter (Top Count; Perkin-Elmer).

The drug concentration able to inhibit $50 \%$ of parasite growth $\left(\mathrm{IC}_{50}\right)$ was assessed by the drug concentration corresponding to $50 \%$ of the incorporation of tritiated hypoxanthine by the parasite in the drug-free control wells. The $\mathrm{IC}_{50}$ value was determined by non-linear regression analysis of log-based dose-response curves (Riasmart, Packard, Meriden, USA).

\section{Nucleic acid extraction}

Total genomic DNA of each strain was isolated using the QIAamp DNA Mini kit according to the manufacturer's recommendations (Qiagen, Germany).

\section{Pfort single-nucleotide polymorphisms (SNPs)}

A 546-nucleotide fragment of the Pfcrt gene (containing codon 76) was amplified by PCR using CRTP1-sense 5'CCG TTA ATA ATA AAT ACA CGC AG-3' and CRTP1antisense 5'-CGG ATG TTA CAA AAC TAT AGT TAC C-3' primers [22]. The reaction mixture for $\mathrm{PCR}$ amplifications included $2.5 \mu \mathrm{l}$ of genomic DNA, $2.5 \mu \mathrm{l}$ of $10 \mathrm{X}$ reaction buffer (Eurogentec), $0.5 \mu \mathrm{M}$ of each primer, $200 \mu \mathrm{M}$ of a deoxynucleoside triphosphate mixture (dGTP, dATP, dTTP and dCTP) (Euromedex, Souffelweyersheim, France), $2.5 \mathrm{mM} \mathrm{MgCl}_{2}$ and 1 unit of RedGoldStar DNA polymerase (Eurogentec) in a final volume of $25 \mu \mathrm{l}$. The thermal cycler (T3 Biometra, Archamps, France) was programmed as follows: an initial $94^{\circ} \mathrm{C}$ incubation for $5 \mathrm{~min}, 40$ cycles of $94^{\circ} \mathrm{C}$ for $20 \mathrm{sec}, 56^{\circ} \mathrm{C}$ for $20 \mathrm{sec}, 60^{\circ} \mathrm{C}$ for $40 \mathrm{sec}$, and a final 5 -min extension step at $60^{\circ} \mathrm{C}$. The PCR products were loaded on a $1.5 \%$ agarose gel containing $0.5 \mu \mathrm{g} / \mathrm{mL}$ ethidium bromide. The PCR products were diluted 1:100 in distilled water, and $2.5 \mu \mathrm{l}$ of the final dilution was used for the second PCR. This PCR amplified a 275 bp segment around the mutation using a common inner primer CRTP3-sense 5'-TGA CGA GCG TTA TAG AG-3' coupled with either CRTP4mantisense 5'-GTT CTT TTA GCA AAA ATT G-3' (detects the 76 T codon) or CRTP4w-antisense $5^{\prime}$-GTT CTT TTA GCA AAA ATT T-3' (detects the $76 \mathrm{~K}$ codon). The reaction mixture for the PCR amplifications included $2.5 \mu \mathrm{l}$ of diluted PCR product, $2.5 \mu \mathrm{l}$ of $10 \mathrm{X}$ reaction buffer (Eurogentec), $0.5 \mu \mathrm{M}$ of each primer, $200 \mu \mathrm{M}$ deoxynucleoside triphosphate mixture (dGTP, dATP, dTTP and dCTP) (Euromedex, Souffelweyersheim, France), $1.5 \mathrm{mM}$ $\mathrm{MgCl}_{2}$ and $0.75 \mathrm{U}$ of RedGoldStar DNA polymerase (Eurogentec) in a final volume of $25 \mu \mathrm{l}$.

The PCR conditions were at $94^{\circ} \mathrm{C}$ for $5 \mathrm{~min}, 15$ cycles at $94^{\circ} \mathrm{C}$ for $20 \mathrm{sec}, 48.5^{\circ} \mathrm{C}$ for $20 \mathrm{sec}, 64^{\circ} \mathrm{C}$ for $40 \mathrm{sec}$, and a final 5-min extension step at $64^{\circ} \mathrm{C}$. Purified genomic DNA from $P$. falciparum clones 3D7 (chloroquine susceptible) and W2 (chloroquine resistant) were used as positive controls, and water and human DNA were used as negative controls. The PCR products from the amplification reactions were evaluated by electrophoresis on $2 \%$ agarose gels.

\section{Statistical analysis}

Data were analysed using $\mathrm{R}$ software (version 2.10.1). Assessment of standard anti-malarial drugs cross-resistance between piperaquine and chloroquine drugs was measured by pairwise correlation of $\mathrm{IC}_{50}$ values of all isolates and estimated by coefficient of correlation of Pearson $(r)$ and coefficient of determination $\left(r^{2}\right)$. Differences between the chloroquine and piperaquine $\mathrm{IC}_{50}$ values of isolates and Pfcrt K76T were compared using the Mann Whitney $\mathrm{U}$ test.

\section{Results}

The $\mathrm{IC}_{50}$ for piperaquine ranged from $9.8 \mathrm{nM}$ to $217.3 \mathrm{nM}$ $($ mean $=81.3 \mathrm{nM}$; 95\% confidence interval 71.3-92.7). The $\mathrm{IC}_{50}$ for chloroquine ranged from $5.0 \mathrm{nM}$ to $1918 \mathrm{nM}$ ( mean $=83.6 \mathrm{nM}$; 95\% confidence interval 71.0-98.3). Fifty three\% of the isolates showed $\mathrm{IC}_{50}>100 \mathrm{nM}$ for chloroquine. A significant correlation was observed between the $\log \mathrm{IC}_{50}$ values for piperaquine and chloroquine $(\mathrm{r}=0.145$, $\mathrm{p}<0.001$ ) (Figure 1).

Of the 280 isolates, 125 were wild type (K76), and 155 were mutated $(76 \mathrm{~T})$. The mean value for chloroquine $\mathrm{IC}_{50}$ was $31.3 \mathrm{nM}$ (95\% CI 25.4-38.7) in the wild-type group and 184.5 (95\% CI 157.4-215.8) in the mutant group. This difference was significant $(\mathrm{p}=0.001$, Mann Whitney $U$ test). The mean value for piperaquine was $74.0 \mathrm{nM}(95 \%$ 


\section{$\mathrm{Y}=1.654+0.06 * \mathrm{X}, \mathrm{r}^{2}=0.021$}

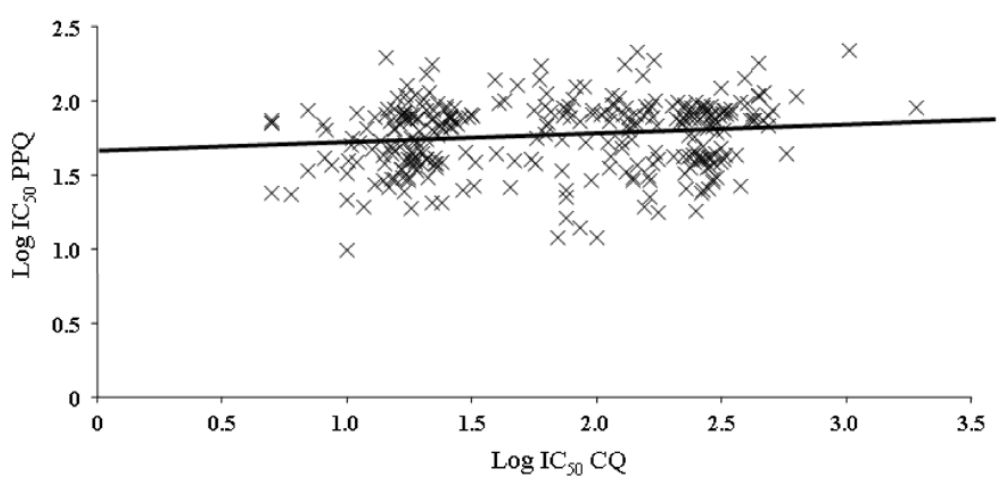

Figure 1 Pearson's correlation analysis of the $\log \mathrm{IC}_{50}$ values of piperaquine and chloroquine.

CI 62.9-87.0) in the wild-type group and 87.7 (95\% CI 71.9-106.9) in the mutant group. This difference was not significant ( $\mathrm{p}=0.875$, Mann Whitney $\mathrm{U}$ test).

\section{Discussion}

The $\mathrm{IC}_{50}$ for piperaquine ranged from $9.8 \mathrm{nM}$ to 217.3 $\mathrm{nM}$ (mean $=81.3 \mathrm{nM}$; 95\% confidence interval 71.3-92.7). These values are greater than the geometric means for isolates from Cameroon (geometric mean $=39 \mathrm{nM}$ ) [13], the Thai-Burmese border (49 nM) [23], Kenya (50 nM) [15], Uganda $(6.1 \mathrm{nM})$ [14], Indonesia $(21.8 \mathrm{nM})$ [24], and Papua New Guinea [12]. The comparison of $\mathrm{IC}_{50} \mathrm{~s}$ across studies is likely hampered by different methodology in assessing these. The isolate with the highest $\mathrm{IC}_{50}$ for piperaquine $(217.3 \mathrm{nM})$ was also resistant to chloroquine $(1,029 \mathrm{nM})$. There is no consensus threshold indicating piperaquine in vitro resistance or reduced susceptibility.

In vitro cross-resistance was assessed using the pairwise correlation of the $\log \mathrm{IC}_{50}$ values of the 280 isolates (Figure 1). A significant correlation was observed between the $\log \mathrm{IC}_{50}$ values for piperaquine and chloroquine $(\mathrm{r}=$ $0.145, \mathrm{p}<0.001)$. However, this value is too low to suggest that there is cross-resistance between piperaquine and chloroquine. For a correlation to imply that two compounds share common mechanisms of action or resistance, which could induce cross-resistance, the coefficient of determination $\left(\mathrm{r}^{2}\right)$ must be high. Here, the coefficient of determination of 0.021 indicates that only $2.1 \%$ of the variation in the response to piperaquine is explained by the variation in the response to chloroquine. These data are in accordance with the majority of the previous studies, which found weak coefficients of determination [13-17]. This result suggests that piperaquine and chloroquine do not share common mechanisms of resistance. However, positive significant correlation was found for 63 isolates from the China-Myanmar border area $(\mathrm{r}=0.79, \mathrm{p}<0.0001)$ [11] and 54 isolates from Papua New Guinea $(\mathrm{r}=0.51, \mathrm{p}<0.001)$
[12]. This difference in in vitro cross-resistance might be explained by the low sample numbers in these two studies and by geographical strain differences.

As expected, the 76T mutation is associated with chloroquine resistance $(\mathrm{p}=0.001$, Kruskal-Wallis test). The mean value for piperaquine was $74.0 \mathrm{nM}$ (95\% CI 62.9-87.0) in the wild-type group and 87.7 (95\% CI 71.9-106.9) in the mutant group. This difference was not significant $(\mathrm{p}=$ 0.862 , Kruskal-Wallis test). These data suggest that the $76 \mathrm{~T}$ mutation is not associated with piperaquine-decreased susceptibility. These data are in accordance with previous data on 23 strains from 15 countries of Africa, Asia and South America [16] and 115 isolates from Kenya [15]. The absence of cross-resistance between piperaquine and chloroquine may be explained by the absence of an association between piperaquine resistance and pfcrt. The very weak correlation between piperaquine and chloroquine responses (only $2.1 \%$ of the variation in the response to piperaquine is explained by the variation in the response to chloroquine) could be explained by other polymorphisms involved in very minor way in chloroquine resistance, such as pfmdr1 SNPs or copy number. Fieldwork has shown that the predictive value for chloroquine resistance and point mutations in the pfmdr1 sequence resulting in amino acid changes varies depending on the geographic area $[25,26]$. Point mutations, most notably N86Y, have been associated with a decrease in the chloroquine susceptibility [27]. However, in some of these epidemiological studies, the number of chloroquine-susceptible samples is too limited to provide statistically meaningful analysis $[26,28]$. Using precautions, no or only weak relationships are established in P. falciparum between chloroquine resistance and mutations in pfmdr1 [25]. However, previous works demonstrated that polymorphisms in pfmdr1 gene or copy number are not associated with decreased susceptibility to piperaquine $[11,15,16]$. 
These field results are in contrast to experimental data that showed that genetically modified parasites with CVIET haplotypes had reduced susceptibility to piperaquine [29].

The present work demonstrated that piperaquine exhibits currently no cross-resistance with chloroquine in African $P$. falciparum isolates and that resistance to piperaquine is not associated with pfcrt, the gene involved in chloroquine resistance. The validity of this conclusion should be further supported by analysing more isolates, especially from South America and Asia. In addition, copy number variation of a chromosome 5 region, a genetic marker associated with high piperaquine $\mathrm{IC}_{50}$ in a piperaquine-selected $P$. falciparum line [30], should be evaluated for reduced ex vivo susceptibility. Nevertheless, these results confirm the efficacy of piperaquine in association with dihydroartemisinin and support its use in areas in which parasites are resistant to chloroquine.

\section{Competing interests}

All authors declare that they have no competing interests.

\section{Authors' contributions}

MM, LB, NB, and JC carried out the molecular genetic studies. AP, RA and DT carried out the ex vivo evaluation of doxycycline susceptibility. The French National Reference Centre for Imported Malaria Study Group supervised, carried out and coordinated the field collections of patient isolates. NT, DP and $\mathrm{BP}$ conceived and coordinated the study. CR and BP analysed the data. $A P, M M, N T, C R, D P$, and BP drafted the manuscript. All the authors read and approved the final manuscript.

\section{Authors' information}

French National Reference Centre for Imported Malaria Study Group: $\checkmark$ Augis (CHU de Bordeaux, Bordeaux), D Basset (CHU Lapeyronnie, Montpellier), F Benoit-Vical (CHU de Rangueil, Toulouse), A Berry (CHU de Rangueil, Toulouse), N Bourgeois (CHU Caremeau, Nimes), F Conquere de Monbrison (CHU de Lyon, Lyon), P Delaunay (CHU de l'Archet, Nice), J Delmont (Hôpital Nord, Marseille), K Ezzedine (CHU de Bordeaux, Bordeaux), B Faugere (CHU La Timone, Marseille), T Gaillard (HIA Saint-Anne, Toulon), C Garabedian ( $\mathrm{CH}$ du Pays d'Aix, Aix en Provence), D Malvy (CHU de Bordeaux, Bordeaux), P Marty (CHU de l'Archet, Nice), D Maubon (CHU de Grenoble 1, Grenoble), G Menard (HIA Saint-Anne, Toulon), P Millet (CHU de Bordeaux, Bordeaux), P Minodier (Hôpital Nord, Marseille), Montaut ( $\mathrm{CH}$ de Pau, Pau), A Mottard (Hôpital de Fréjus-Saint Raphael, Fréjus), P Munier (CH de Valence, Valence), P Parola (Hôpital Nord, Marseille), S Picot (UMR 5246 CNRS, Lyon), T Pistone (CHU de Bordeaux, Bordeaux), C Pomares-Estran (CHU de l'Archet, Nice), J Puyhardy (HIA Legouest, Metz), D Raffenot (CH de Chambéry, Chambéry), M-C Receveur (CHU de Bordeaux, Bordeaux), H Savini (HIA Laveran, Marseille),

F Simon (HIA Laveran, Marseille), S Vedy (HIA Legouest, Metz).

\section{Acknowledgements}

This study was supported by the Institut de Veille Sanitaire (grant number CNR paludisme).

\section{Author details}

${ }^{1}$ Département d'Infectiologie de Terrain, Unité de Parasitologie, Institut de Recherche Biomédicale des Armées, Marseille, France. ${ }^{2}$ Aix Marseille Université, Unité de Recherche sur les Maladies Infectieuses et Tropicales Emergentes, UM 63, CNRS 7278, IRD 198, Inserm 1095, Marseille, France. ${ }^{3}$ Centre National de Référence du Paludisme, Marseille, France. ${ }^{4}$ UMR MD3, Aix Marseille Université, Institut de Recherche Biomédicale des Armées, Marseille, France. ${ }^{5}$ Equipe Résidente de Recherche en Infectiologie Tropicale, Institut de Recherche Biomédicale des Armées, Hôpital d'Instruction des Armées Laveran, Marseille, France. ${ }^{6}$ Institut Pasteur de Madagascar, Antananarivo, Madagascar.
Received: 4 July 2013 Accepted: 22 November 2013

Published: 25 November 2013

\section{References}

1. Le Bras J, Musset L, Clain J: Antimalarial drug resistance. Med Mal Infect 2006, 36:401-405.

2. Smithuis F, Kyaw MK, Phe O, Aye KZ, Htet L, Barends M, Lindegardh N, Singtoroj T, Ashley E, Lwin S, Stepniewska K, White NJ: Efficacy and effectiveness of dihydroartemisinin-piperaquine versus artesunate-mefloquine in falciparum malaria: an open label randomized comparison. Lancet 2006, 367:2075-2085.

3. Thang NX, Trung TN, Phong NC, Quang HH, Dai B, Shanks GD, Chavchich M, Edstein MD: The efficacy and tolerability of artemisinin-piperaquine (Artequick) versus artesunate-amodiaquine (Coarsucam) for the treatment of uncomplicated Plasmodium falciparum malaria in south-central Vietnam. Malar J 2012, 11:217.

4. Yavo W, Faye B, Kuete T, Djohan V, Oga SA, Kassi RR, Diatta M, Ama MV, Tine R, Ndiaye JL, Evi JB, Same-Ekobo A, Faye O, Koné M: Multicentric assessment of the efficacy and tolerability of dihydroartemisinin-piperaquine compared to artemether-lumefantrine in the treatment of uncomplicated Plasmodium falciparum malaria in sub-Saharan Africa. Malar J 2011, 10:198.

5. Yeka A, Tibenderana J, Achan J, D'Alessandro U, Talisuna AO: Efficacy of quinine, artemether-lumefantrine and dihydroartemisinin-piperaquine as rescue treatment for uncomplicated malaria in Ugandan children. PLoS One 2013, 8:53772.

6. Yeka A, Dorsey G, Kamya MR, Talisuna A, Lugemwa M, Rwakimari JB, Staedke SG, Rosenthal PJ, Wabwire-Mangen F, Bukirwa H: Artemether-lumefantrine versus dihydroartemisinin-piperaquine for treating uncomplicated malaria: a randomized trial to guide policy in Uganda. PLoS One 2008, 3:2390.

7. Kamya MR, Yeka A, Burkirwa H, Lugemwa M, Rwakimari JB, Staedke SG, Talisuna AO, Greenhouse B, Nosten F, Rosenthal PJ, Wabwire-Mangen F, Dorsey G: Artemether-lumefantrine versus dihydroartemisininpiperaquine for treatment of malaria: a randomized trial. PLOS Clin Trials 2007, 2:e20

8. Zongo I, Dorsey G, Rouamba N, Dokomajilar C, Séré Y, Rosenthal PJ, Ouédraogo JB: Randomized comparison of amodiaquine plus sulfadoxine-pyrimethamine, artemether-lumefantrine, and dihydroartemisinin-piperaquine for the treatment of uncomplicated Plasmodium falciparum malaria in Burkina-Faso. Clin Infect Dis 2007, 45:1453-1461.

9. Hasugian AR, Purba HLE, Kenangalem E, Wuwung RM, Ebsworth EP, Maristela R, Penttinen PMP, Laihad F, Anstey NM, Tjitra E, Price RN: Dihydroartemisinin-piperaquine versus artesunate-amodiaquine: superior efficacy and posttreatment prophylaxis against multidrug resistant Plasmodium falciparum and Plasmodium vivax malaria. Clin Infect Dis 2008, 44:1067-1074.

10. Davis TM, Hung TY, Sim IK, Karunajeewa HA, Ilett KF: Piperaquine: a resurgent antimalarial drug. Drugs 2005, 65:75-87.

11. Hao M, Jia D, Li Q, He Y, Yuan L, Xu S, Chen K, Wu J, Shen L, Sun L, Zhao H, Yang $Z$, Cui $L$ : In vitro sensitivities of Plasmodium falciparum isolates from the China-Myanmar border to piperaquine and association with polymorphisms in candidate genes. Antimicrob Agents Chemother 2013, 57:1723-1729.

12. Wong RPM, Lautu D, Tavul L, Hackett SL, Siba P, Karunajeewa HA, Ilett KF, Mueller I, Davis TME: In vitro sensitivity of Plasmodium falciparum to conventional and novel antimalarial drugs in Papua New Guinea. Trop Med Int Health 2010, 15:342-349.

13. Basco LK, Ringwald $P$ : In vitro activities of piperaquine and other 4-aminoquinolines against clinical isolates of Plasmodium falciparum in Cameroon. Antimicrob Agents Chemother 2003, 47:1391-1394.

14. Nsobya SL, Kiggundu M, Nanyunja S, Joloba M, Greenhouse B, Rosenthal PJ: In vitro sensitivity of Plasmodium falciparum to different antimalarial drugs in Uganda. Antimicrob Agents Chemother 2010, 54:1200-1206.

15. Mwai L, Kiara SM, Abdirahman A, Pole L, Rippert A, Diriye A, Bull P, Marsh K, Borrmann S, Nzila A: In vitro activities of piperaquine, lumefantrine, and dihydroartemisinin in Kenyan Plasmodium falciparum isolates and polymorphisms in pfcrt and pfmdr1. Antimicrob Agents Chemother 2009, 55:5069-5073.

16. Briolant S, Henry M, Oeuvray C, Amalvict R, Baret E, Didillon E, Rogier C, Pradines $B$ : Absence of association between piperaquine in vitro responses and polymorphisms in the pfcrt, pfmdr1, pfmrp, and pfnhe 
genes in Plasmodium falciparum. Antimicrob Agents Chemother 2010, 54:3537-3544

17. Pascual A, Parola P, Benoit-Vical F, Simon F, Malvy D, Picot S, Delaunay P, Basset D, Maubon D, Faugère B, Ménard G, Bourgeois N, Oeuvray C, Didillon $E$, Rogier C, Pradines B: Ex vivo activity of the ACT new components pyronaridine and piperaquine in comparison with conventional ACT drugs against isolates of Plasmodium falciparum. Malar J 2012, 11:45.

18. Fidock DA, Nomura T, Talley AK, Cooper RA, Dzekunov SM, Ferdig MT, Ursos LM, Sidhu AB, Naudé B, Deitsch KW, Su XZ, Wootton JC, Roepe PD, Wellems TE: Mutations in the $P$. falciparum digestive vacuole transmembrane protein PfCRT and evidence for their role in chloroquine resistance. Mol Cell 2000, 6:861-871.

19. Lambros C, Vanderberg JP: Synchronization of Plasmodium falciparum erythrocytic stages in culture. J Parasitol 1979, 65:418-420.

20. Bogreau H, Renaud F, Bouchiba H, Durand P, Assi SB, Henry MC, Garnotel E, Pradines B, Fusai T, Wade B, Adehossi E, Parola P, Kamil MO, Puijalon O, Rogier C: Genetic diversity and structure of African Plasmodium falciparum populations in urban and rural areas. Am J Trop Med Hyg 2006, 74:953-959.

21. Henry M, Diallo I, Bordes J, Ka S, Pradines B, Diatta B, M'Baye PS, Sane M, Thiam M, Gueye PM, Wade B, Touze JE, Debonne JM, Rogier C, Fusai T: Urban malaria in Dakar, Senegal: chemosusceptibility and genetic diversity of Plasmodium falciparum isolates. Am J Trop Med Hyg 2006, 75:146-151.

22. Tinto H, Ouédraogo JB, Erhart A, van Overmeir C, Dujardin JC, van Marck E, Guiguemdé TR, D'Alessandro U: Relationship between the Pfcrt T76 and the Pfmdr-1 Y86 mutations in Plasmodium falciparum and in vitro/ in vivo chloroquine resistance in Burkina Faso, West Africa. Infect Genet Evol 2003, 3:287-292.

23. Barends M, Jaidee A, Khaohirun N, Singhasivanon P, Nosten F: In vitro activity of ferroquine (SSR 97193) against Plasmodium falciparum isolates from the Thai-Burmese border. Malar J 2007, 6:81.

24. Marfurt J, Chalfein F, Prayoga P, Wabiser F, Kenangalem E, Piear KA, MacHunter B, Tjitra E, Anstey NM, Price RN: Ex vivo drug susceptibility of ferroquine against chloroquine-resistant isolates of Plasmodium falciparum and P. vivax. Antimicrob Agents Chemother 2011, 55:4461-4464.

25. Basco LK, Ringwald P: Molecular epidemiology of malaria in Yaoundé, Cameroon. III. Analysis of chloroquine resistance and point mutations in the multidrug resistance 1 (pfmdr 1) gene of Plasmodium falciparum. Am J Trop Med Hyg 1998, 59:577-581.

26. Duraisingh MT, Drakeley CJ, Muller O, Bailey R, Snounou G, Targett GA, Greenwood BM, Warhurst DC: Evidence for selection for the tyrosine-86 allele of the pfmdr 1 gene of Plasmodium falciparum by chloroquine and amodiaquine. Parasitology 1997, 114:205-211.

27. Foote SJ, Kyle DE, Martin RK, Oduola AM, Forsyth K, Kemp DJ, Cowman AF: Several alleles of the multidrug-resistance gene are closely linked to chloroquine resistance. Nature 1990, 345:255-258.

28. Grobusch MP, Adagu IS, Kremsner PG, Warhurst DC: Plasmodium falciparum: in vitro chloroquine susceptibility and allele-specific PCR detection of Pfmdr1 Asn86Tyr polymorphism in Lambarene, Gabon. Parasitology 1998, 116:211-217.

29. Muangnoicharoen S, Johnson DJ, Looareesuwan S, Krudsood S, Ward SA: Role of known molecular markers of resistance in the antimalarial potency of piperaquine and dihydroartemisinin in vitro. Antimicrob Agents Chemother 2009, 53:1362-1366.

30. Eastman RT, Dharia NV, Winzeler EA, Fidock DA: Piperaquine resistance is associated with a copy number variation on chromosome 5 in drug-pressured Plasmodium falciparum parasites. Antimicrob Agents Chemother 2011, 55:3908-3916.

doi:10.1186/1475-2875-12-431

Cite this article as: Pascual et al:: In vitro piperaquine susceptibility is not associated with the Plasmodium falciparum chloroquine resistance transporter gene. Malaria Journal 2013 12:431.

\section{Submit your next manuscript to BioMed Central and take full advantage of:}

- Convenient online submission

- Thorough peer review

- No space constraints or color figure charges

- Immediate publication on acceptance

- Inclusion in PubMed, CAS, Scopus and Google Scholar

- Research which is freely available for redistribution

Submit your manuscript at www.biomedcentral.com/submit
C Biomed Central 